\title{
TRADUÇÃO E REFERÊNCIAS CULTURAIS
}

\author{
Mônica Cristina Corrêa \\ Tradutora \\ monicris@uol.com.br
}

\begin{abstract}
Resumo: Este artigo discute o problema da tradução das referências culturais por meio de exemplos tirados de experiências pessoais da autora. À luz das concepções de Laurence Venuti e André Lefevere, visa-se debater a traduzibilidade dos dados culturais à medida que ultrapassam os limites da língua. Refletimos, ainda, sobre as consequências de algumas opções no tocante à tradução das referências culturais, uma vez que elas desembocam, quase sempre, na formação de uma imagem do Outro.
\end{abstract}

Palavras-chave: tradução, literatura, língua francesa, língua portuguesa.

\begin{abstract}
This article discusses translation's problems about cultural references, through examples taken from the author's personal experience. Employing Laurence Venuti's and André Lefevere's conceptualization about he subject, we aim to discuss the translatability of the ways of translating cultural data which go beyond language constraints. We also takes into consideration that these data cross the language's frontiers. We also propose to think about the consequences of translation choices concerning cultural data or references, since most of them choices contribute to elaborate an image of the Other.
\end{abstract}

Keywords: translation, literature, French language, Portuguese language.

Para contar minha vida de merda, minha vida de puteiro, num fala aproximada, num francês que dê para o gasto, para não meter os pés pelas mãos com um monte de palavrões, eu possuo quatro dicionários. Primeiro o dicionário Larousse e o Petit Robert, segundo o Inventário das particularidades lexicais do francês da África negra e terceiro, o dicionário 
Harrap's. Esses dicionários me servem para procurar os palavrões, para verificar os palavrões e principalmente para explicá-los. É preciso explicar porque meu blá-blá-blá é para ser lido por todo tipo de gente: tubabs (tubab significa branco) colonos, pretos nativos selvagens da África e francófonos de tudo que é gabarito (gabarito significa tipo). O Larousse e o Petit Robert me servem para procurar, verificar e explicar os palavrões do francês da França aos pretos nativos da África. O Inventário das particularidades lexicais do francês da África explica os palavrões africanos aos tubabs franceses da França. O dicionário Harrap's explica os palavrões pidgin a todo francófono que não entende nada de pidgin ${ }^{1}$.

O excerto acima é do romance do escritor da Costa do Marfim, Amadou Kouroma, Alá e as crianças soldado (Seuil, 2000), cuja tradução brasileira, de Flávia do Nascimento, recebeu o prêmio FNAC de melhor obra traduzida do francês no ano de 2003, quando de seu lançamento.

Numa espécie de prólogo, o narrador, como uma debochada forma de advertência, tenta expor ao leitor toda a dificuldade que teria passado para tornar sua mensagem compreensível a mais de um universo cultural, ou seja, o dos africanos e suas diversidades intrínsecas, e o dos francófonos da França e possivelmente de outras colônias. Ao longo do romance, o narrador usará parêntesis todas as vezes que uma expressão lhe parecer difícil ou estranha a cada uma dessas possíveis culturas, ou quando desejar que suas referências culturais, sobretudo as africanas, sejam bem entendidas, como no caso desses dois outros exemplos:

Simplesmente, Ma [como se refere à sua mãe], que isso vinha do fundo do meu ventre, como dizem os africanos, ou do meu coração, como dizem os franceses da França ${ }^{2}$.

As crianças soldados estavam furiosas, vermelhas de tão furiosas (A gente não deve dizer vermelho de furioso no caso 
dos pretos. Os pretos nunca ficam vermelhos, eles ficam carrancudos) $)^{3}$.

Ora, o instigante jogo que Kouroma faz com a linguagem consiste em, por ela, levar às últimas consequências o estado de dilaceramento do sujeito entre duas culturas - uma em que se expressa, outra que lhe é materna; portanto, intrínseca e indelével -, poderia ensejar toda uma argumentação acerca da traduzibilidade das referências culturais.

$\mathrm{O}$ ato tradutório se mostra, de fato, frequentemente, um ato de divisão do sujeito-tradutor, obrigado a fazer escolhas que veiculem elementos culturais do original de que parte, sem correlação imediata em sua própria língua-cultura; noutras instâncias, o mesmo tradutor poderá optar por fazer certa assimilação desses elementos, buscando adaptar em seu texto referências similares, caso as encontre em sua própria cultura. As implicações dessas opções serão todas ligadas aos modos de traduzir, os quais não serão exclusivamente dependentes dessa fase, mas determinados também pelos resultados pretendidos.

Na literatura, Kouroma consegue fazer com que o leitor se dê conta, antes de tudo, do sofrimento do narrador: a expressão linguística, a língua em sua profunda insuficiência, apoiada em tantos dicionários também ineficazes por suas limitações, é uma espécie de materialização de sua voz afogada sob a constante estrangeirização de seus sentimentos. E sentimentos, por sua própria natureza, nem poderiam ser transmitidos pela palavra/forma.

Por meio da voz do personagem, o autor africano revela a impotência da língua que lhe foi imposta pela antiga metrópole quando da necessidade de expressar-se com clareza. E da língua materna, menor e talvez sem escrita, em se fazer escutar. No livro $A$ capital mundial das letras ${ }^{4}$, a estudiosa Pascale Casanova menciona esse tipo de manifestação (em que o autor escreve na língua de sua metrópole) e a explica como sendo antes de tudo um fator social: alguns escritores, desejando obter o prestígio literário, passam a se 
exprimir em línguas de culturas hegemônicas, como é o caso do francês e da França. É uma forma de sair do ostracismo literário a que ficam condenados alguns artistas de países menos favorecidos economicamente. Mas, como é possível perceber, Kourouma vai além, demonstrando nessa língua hegemônica a impossibilidade de expressão completa; ridicularizando, de certa maneira, o totalitarismo exercido pelas culturas de potências mundiais.

De qualquer modo, o autor está sujeito às influências dessas culturas, a dominante e a dominada, e mesmo o fato de se insurgir contra a imposição (linguística sobretudo) não torna inócuas suas consequências. Ao contrário, as influências de um lado e de outro ressaltam sua pertença dilacerada a dois mundos paradoxalmente inseparáveis e distintos. E a influência seria, talvez, apenas um dos aspectos que se pode colocar sob a égide da "referência cultural", com suas múltiplas facetas e resultados. Em matéria de tradução, tais referências se constituem num problema central e literário, mas também atuam fora dele, como procuraremos mostrar mais adiante. $\mathrm{O}$ texto de Amadou Kourouma, justamente por centrar-se na quase inviabilidade da tradução, pareceu-nos bastante ilustrativo dessa problemática. Sem, naturalmente, pretender fazer um estudo exaustivo das implicações que esta tem para a tradução, tentaremos apontar algumas questões que nos parecem sobremaneira relevantes, procurando, à medida do possível, exemplificá-las com base em nossas próprias experiências.

\section{O modo de traduzir e a leitura do Outro:}

Uma primeira implicação cultural e justamente referencial na tradução estaria, ao nosso ver, na própria maneira de traduzir mais ou menos em vigor numa determinada língua-cultura. Segundo estudos de André Lefevere e outros autores, as premissas que norteiam as opções de um tradutor são, normalmente, condizentes com uma ideologia a que ele se filia, em geral, por razões cultu- 
rais. Assim, a primeira referência cultural da tradução está em sua base. Não obstante seja o texto voltado a tal ou qual público, de acordo com determinados valores editoriais, há de imperar, num dado momento histórico, uma maneira de traduzir mais ou menos comum àquele quadro social e cultural. Isso não exclui obviamente que haja propostas independentes do geral; haja vista o caso das traduções universitárias. Mas também estas, ainda que num microssistema, fazem parte de uma tendência e costumam seguir um parâmetro mais ou menos estabelecido.

Evoquemos aqui as palavras do teórico e tradutor Henri Meschonnic: "Os franceses não traduzem os russos como os russos traduzem os franceses" ${ }^{5}$. Meschonnic analisa que não há uma contemporaneidade nas maneiras de ler e traduzir o Outro. Assim, uma maneira de traduzir pode se referenciar naquelas de outro país, espelhando, inclusive, certas assimilações.

Dois estudos atestam, por exemplo, no Brasil, uma certa maneira de traduzir que muito se preocupou em refletir nos textos de chegada a cultura francesa, por estar esta na base da formação cultural brasileira. Trata-se dos estudos de Lia Wyler ${ }^{6}$ sobre a história da tradução no Brasil e de John Milton ${ }^{7}$, que analisou as traduções realizadas pelo antigo Círculo do Livro no país. Ambos os autores percebem que, até o fim da Segunda Guerra Mundial, o Brasil teve por capital cultural a França e essa referência influenciou o modus vivendi da aristocracia nacional e o de sua burguesia ascendente, mostrando-se também nas manifestações literárias e escritas. Espelhar a França, imitá-la, segui-la; o lema valia para as letras. Eis uma primeira referência cultural nas traduções brasileiras.

Por outro lado, conforme a tese de Pascale Casanova, o mesmo não tende a acontecer nos países ditos de cultura hegemônica. Ao analisar o papel de capital centralizadora da predominância da língua francesa e da literatura de Paris, a autora abre caminho para que se compreenda uma atitude quase inversa àquela verificada em países menos poderosos economicamente: o modo de traduzir da França se inclinaria à nacionalização, visando ao apagamento de tudo que soasse estrangeiro. Se tal maneira se denominou, histo- 
ricamente, como "les belles infidèles" nos séculos XVII e XVIII sobretudo, a continuidade do poderio francês, malgrado sua perda de espaço para os EUA, se manifesta ainda, muitas vezes, numa maneira de traduzir que ainda é semelhante às tais belles ou que nacionaliza o estrangeiro. Lida-se de maneira diferente daquela dos países não hegemônicos com as referências culturais. Veja-se o que diz Laurence Venuti, em Escândalos da tradução:

Nos países hegemônicos, a tradução modela imagens de seus Outros subordinados, que podem variar entre os polos do narcisismo e da autocrítica (...). Nos países em desenvolvimento, a tradução modela imagens de seus Outros hegemônicos e deles próprios que podem tanto clamar por submissão, colaboração, ou resistência, que podem assimilar valores estrangeiros dominantes $(\ldots)^{8}$.

Destarte, há de se pensar que a imagem e a representatividade que um país tem de outro também influem diretamente em seu modo de traduzi-lo - e é exatamente traduzir um país e não apenas sua língua -, já que tal imagem está sempre atrelada a uma ideologia de cunho sociocultural. E em virtude da característica dessa relação, isto é, da leitura de um e de outro, ou seja, das referências culturais, serão determinados os modos de traduzir. Por vários métodos (omissão, exclusão, nacionalização, adaptação, etc.), poderá haver apagamento e assimilação da alteridade quando da tradução, ou, ao contrário, haverá ênfase a estrangeirismos de toda sorte para valorizar-se a origem de um dado texto.

\section{Destino das referências culturais na tradução: Domesticação x Estrangeirismos}

As referências culturais serão sempre de diversas naturezas, em se considerando, para tal assertiva, que se trata daquilo que há de 
mais intrínseco na expressão de uma determinada cultura, a exemplo do que nos mostra o jogo literário de Amadou Kouroma citado no início deste artigo. Ultrapassam a palavra escrita, podendo estar nos símbolos e outros signos que não o linguístico, o que entraria no campo da tradução intersemiótica.

No quesito das traduções linguísticas, tais referências passam por diversas categorias e, conforme a situação, podem ser completamente ignoradas. Como exemplo, citaríamos a tradução legendada de uma cena do filme francês Les visiteurs. A película é uma hilariante comédia mostrando dois cavaleiros medievais que, num passe de mágica, "despencam" no mundo contemporâneo. Há de se imaginar o choque cultural em todos os níveis, mas o filme não deixa de fazer a sátira na linguagem. Assim, quando um dos personagens se crê em guerra, dá o grito de saudação ao imperador Carlos Magno, que os franceses conhecem bem por "Monjoie" e que aparece na legenda como "Monte Alegre"... Muitos seriam os exemplos de referências culturais que passam despercebidas dos tradutores e do público, sobretudo em legendagem de filmes. Aqui não se trata nem de domesticação nem de estrangeirismo - destinos mais frequentes das referências na tradução - mas de desconhecimento.

Subtraídos, pois, os casos que resvalam em anedotas refletindo ignorância, colocaríamos as referências culturais, enquanto problema de tradução, como um elemento passível de dois destinos, obedecendo às tendências ideológicas de cada cultura, em primeira instância, e às do sujeito-tradutor, que está inserto no contexto destas, mas que também é consciente; portanto, autor de suas escolhas.

Diante de uma referência cultural, ou seja, de qualquer fato que manifeste uma especificidade da cultura de partida, o tradutor terá, em síntese, duas possibilidades diante de si: conservar o aspecto estrangeiro do texto ou nacionalizá-lo, isto é, encontrar uma referência na cultura de chegada que possa substituir o elemento da cultura de partida. Esta última, em geral, fará desvanecer ou esvair-se completamente a referência do original. Para melhor explanar essa 
questão, destacamos três exemplos de experiências que tivemos no domínio da tradução, nas quais o problema se colocou.

Primeiramente, citaríamos um texto não literário: uma entrevista que o biógrafo de Júlio Verne, Jean-Paul Dékiss, realizou com o filósofo francês Michel Serres, a qual foi editada e publicada em 2003 na França e que acabamos de traduzir (em edição pela Berthrand Brasil - Rio de Janeiro). Já no início da obra, o entrevistado, brincando com a etimologia das palavras, atesta que as derivações francesas do latim para nomes terminados em -or naquela língua deram todas em -eur, com exceção da palavra amour, que termina em -our. Daí em diante - e por todo um parágrafo -, Michel Serres relacionará esse dado excepcional com o nascimento do conceito de amor cortês, relacionando-o com a antiga Provença e a língua ali falada, a langue d'Oc. Como tratar desses fatos na tradução para o português do Brasil? Não nos pareceu cabível nenhuma equivalência, pois nada poderia substituir o ideário do amor cortês tão celebrado na Provença medieva. Menos ainda era possível manipular a origem da palavra amour $>$ amor, quando em português, língua também latina, não aconteceu o mesmo. Tampouco se aplicava em português a exceção sobre a qual, segundo Michel Serres, haveria trabalhado Júlio Verne. A solução por que optamos nesse caso foi a de inserir uma nota de rodapé, contendo as duas explicações; inicialmente, sublinhava a diferença de derivação das palavras amour/amor, oriundas, não obstante, da mesma palavra latina. Em seguida, tratamos de falar brevemente do que se entende por langue d'Oc.

Nossa opção se calcou, evidentemente, numa ideologia. Procurou satisfazer, em primeiro lugar, as necessidades que o editor supõe serem as de seu público. Depois, pautou-se em criar uma coerência com o tipo de texto de que se tratava: crítica literária, com o intuito de elucidar as características dos romances vernianos. Embora tal opção desse conta do pretendido, não se pode negar que a inserção dessas notas aponta para certo estrangeirismo, à medida que conserva o elemento de fora; a própria expressão langue d'Oc. Em que pesem as discussões acerca dessa escolha, foi a que nos 
pareceu melhor, segundo um padrão editorial. Lawrence Venuti considera, no entanto, que a inserção de notas corre o risco de limitar o público leitor a uma elite: "acrescentar notas de rodapé à tradução pode restringir o público doméstico a uma elite cultural, visto que as mesmas fazem parte de uma convenção acadêmica" 9 . Decerto, mas é uma maneira de resolver questões de referência cultural. Tratando-se de uma análise de teor acadêmico, pareceunos válida.

Será também o mesmo autor, Venuti, a levantar uma questão que nos parece discutível: "As traduções, em outras palavras, inevitavelmente realizam um trabalho de domesticação" ${ }^{10}$. As domesticações, se estão no nível de notas que explicam alusões, intertextualidade, em suma, referências culturais que devem, por alguma razão, transparecer plenamente na tradução, são, de fato, irrefutáveis. Mas as traduções também podem refletir os estrangeirismos sem se tornarem inteiramente domésticas, isto é, sem apagarem as referências culturais estrangeiras, garantindo o estranhamento do texto. E podem ainda, como infere o próprio Venuti, acarretar o que chamará, com pertinência, de "resíduo". Este, por sua vez, surge muitas vezes à revelia do tradutor e se liga a fatores linguísticos como exemplificaremos mais adiante.

Percorremos, pois, o sentido contrário ao da tradução de Michel Serres, em dois outros textos, desta vez literários: o romance do século XIX, La Petite Fadette, de Geroge Sand (Barcarolla, 2006) e os contos de André Pieyre de Mandiargues, o livro Feu de braise (1959), que traduzimos e está publicado pela editora Iluminuras (2002).

No caso de Geroge Sand, o texto é ambientado no campo e as características dos personagens, bem como sua atmosfera, refletem essa paisagem e seus costumes. No plano da linguagem, vários problemas se colocaram. Vamos citar alguns, como foi o caso da palavra "bessons" significando "gêmeos". Em desuso, e termo regional francês, procurarmos "imitá-la" com a expressão "babaço" que é também regional, mas brasileira. Isso passa, decerto, pelo 
que Venuti chamaria de domesticação. Se escolhemos assim proceder, foi para evitar, por outro lado, uma espécie de pasteurização que ignora dialetos e regionalismos, padronizando uma linguagem. Isso tanto seria uma deformação, no entender do tradutólogo francês Antoine Berman, quanto uma desconsideração da importância dessa linguagem, conforme alerta John Milton: "o dialeto é (visto como) uma simples fachada" 11 . Tal decisão pode refletir um processo de domesticação, mas noutros momentos, a permanência, por exemplo, do nome "Fadette", até por sua sugestão de parentesco com "fada" em português, foi mantido e lembra, também no texto de chegada, o perfil quase esotérico da personagem. Acreditamos que um equilíbrio entre esses posicionamentos no traduzir possa gerar um texto literário, sendo esse o principal objetivo de nosso trabalho então.

Assim, as referências culturais da vida campestre francesa podem ter correlatos, guardadas as devidas proporções, com a brasileira. Um processo de tradução amalgamando duas tendências poderia levar, cremos, a bons resultados.

$\mathrm{O}$ terceiro texto a que nos referiremos aqui, o de Mandiargues, trará a possibilidade de analisarmos o problema da tradução das referências culturais do ponto de vista do que Venuti denominou resíduo doméstico. Nosso intuito, com esse exemplo, é comentar o fato de que, muitas vezes, vem somar-se à tradução um elemento ausente no original e não necessariamente negativo ou indesejável. Trata-se, outrossim, de um exemplo de que a fortuna de uma tradução literária se faz, com efeito, à revelia do original e constitui-se, ela também, numa obra.

$\mathrm{O}$ livro de Mandiargues traz sete contos curtos. O segundo deles, intitulado "Rodogune", traz a história da personagem homônima, que é uma moça muito reservada e solitária vivendo na Sardenha, pescando para si mesma. Tem ela por única companhia um carneiro, o qual enfeita às vezes. Ora, os salineiros locais implicam com tal presença, supondo que a moça tivesse relações sexuais com o animal, julgando com isso que tivesse também parte com o demônio. Essa inferência os leva a assassinar o carneiro numa noite, enquanto a moça dormia. 
O nome do animal, em francês, é bélier, macho não castrado e grande da espécie, em contraposição a mouton. Essa característica de virilidade acentua, no texto original, a ideia das relações insólitas de Rodogune com o bicho. Em português, a opção natural seria carneiro. Mas esta palavra também tem acepções contidas em mouton, podendo significar uma pessoa "passiva, mansa, sem atitude". Assim, somou-se ao termo, em português, um traço ausente no francês. Ao mesmo tempo, está em jogo um outro sentido no original: bélier tem acepção de aríete, antiga máquina de guerra destinada a arrombar portas. Por sua forma fálica, associa-se bélier ao pênis, conotação erótica (por conta da máquina arrombadora) presente no original, sem dúvida. Tal associação é inusitada em português até porque seria improvável chamar um aríete de carneiro. Se a conotação não se perde, fica quase imperceptível. Mas tal referência acabou compensada em outro momento do texto. Uma das denominações do narrador ao carneiro de Rodogune é pécore palavra dessueta em francês e em português (pécora). Em ambas as línguas podem aludir a uma mulher feia, mas em português é forte a conotação de meretriz. O que se chamaria de resíduo, enfim, remete a certos acréscimos muitas vezes inevitáveis na tradução e se fazem por meio de novas referências culturais, dadas, normalmente, pelas associações que cada palavra ou expressão carrega diferentemente em culturas de línguas-culturas distintas.

\section{Resultados das referências culturais: Imagens}

Podemos concluir, neste pequeno trabalho, que a tradução de imagens tem implicações diferenciadas no texto de chegada, sobretudo pela análise dessas duas tendências de solução: domesticação ou estrangeirização. Obviamente, não pretendemos, com isso, fazer uma classificação estanque das possibilidades de tradução das referências, mas um recorte pelo qual visamos apontar alguns casos ilustrativos de suas dificuldades. 
Restaria, pois, comentar seus desdobramentos quando o texto está traduzido e publicado na língua-alvo. Pensamos que a maior consequência das referências culturais, seu apagamento ou ênfase, incidirá sobre as imagens de uma cultura para outra. Nesse sentido, as imagens preexistentes do Outro na cultura de chegada podem ser reforçadas segundo estereótipos, preconceitos ou enobrecimento do estrangeiro. Como percebe Venuti, "a tradução exerce um poder enorme na construção de representação de culturas estrangeiras" ${ }^{12}$. Essas representações, cremos, vivificam as relações humanas, definem o perfil de um povo sobre outro. Em sendo ideológicas, não estão sempre em conexão com a realidade, mas é, por outro lado, por meio das imagens que se tece diplomacia e se originam os confrontos.

Destarte, talvez não seja exagero atribuir um papel relevante à tradução das referências culturais nesse cenário. André Lefevere, que entende a tradução como uma poderosa forma de manipulação pela reescritura, assinala: "Tradução é obviamente o tipo mais reconhecível de reescritura e potencialmente a mais influente porque tem capacidade de projetar numa imagem do autor/ou seus trabalhos numa outra cultura(...)"13 [nossa tradução].

E tal imagem, perene ou não, será, sem dúvida, fundamental nos estudos tradutológicos, com seus reflexos para as ciências e a humanidade. Assim, a quimera do narrador do livro de Kourouma - a de fazer-se entender por todos e narrar sua identidade - talvez se realize, aos poucos, no destino da humanidade e em seu desejo de eternizar-se por meio dos textos, mesmo que se tenha de, como o pequeno personagem africano, transladar todo o tempo entre as impossibilidades linguísticas, pois é dessa busca incessante que nascem, talvez, os textos. E esses serão constante e invariavelmente traduzidos e refeitos. 


\section{Notas}

1. KOUROMA, Amadou. Alá e as crianças soldados. Trad. Flávia Nascimento. São Paulo: Estação Liberdade, 2003, p. 11.

2. Idem, p. 19

3. Idem, p. 57.

4. CASANOVA, Pascale. A república mundial das letras. Trad. Marina Appenzeller. São Paulo: Estação Liberdade, 2002.

5. MESCHONNIC, H. Pour la poétique Paris. Trad. Lúcia Barroso Motta e Silva. Paris: Gallimard, 1993, p. 18.

6. WYLER, Lia. Poetas e bacharéis: uma crônica da tradução no Brasil. Rio de Janeiro: Rocco, 2003.

7. MILTON, John. O clube do livro e a tradução. Bauru: EDUSC, 2002.

8. VENUTI, L. Escândalos da tradução. Trad. Laurino Pelegrin et alt., Bauru: EDUSC, 2002, p. 299.

9. Op. cit., p. 47.

10. Op. cit, p. 17.

11. Op. cit., p. 56.

12. Op. cit., p. 130.

13. LEFEVERE, André. Translation, rewriting and the manipulation of literary fame. Londres/Nova York: Routledge, 1992, p. 17. 


\section{Bibliografia}

CASANOVA, Pascale. A república mundial das letras. Trad. Marina Appenzeller. São Paulo: Estação Liberdade, 2002.

KOUROMA, Amadou. Alá e as crianças soldados. Trad. Flávia Nascimento. São Paulo: Estação Liberdade, 2003.

LEFEVERE, André. Translation, rewriting and the manipulation of literary fame. Londres/Nova York: Routledge, 1992, p. 17.

MESCHONNIC, H., Pour la poétique Paris. Trad. Lúcia Barroso Motta e Silva. Paris: Gallimard, 1993, p. 18.

MILTON, John. O clube do livro e a tradução. Bauru: EDUSC, 2002.

VENUTI, L. Escândalos da tradução. Trad. Laurino Pelegrin et al. Bauru: EDUSC, 2002.

WYLER, Lia. Poetas e bacharéis: uma crônica da tradução no Brasil. Rio de Janeiro: Rocco, 2003. 